Kai A. Konrad

Florian Morath

\title{
To deter or to moderate? Alliance formation in contests with incomplete information
}

Max Planck Institute for Tax Law and Public Finance

Working Paper 2015 - 15

December 2015

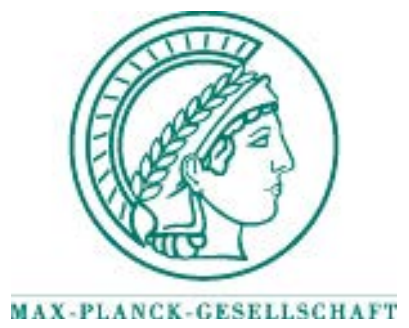

Max Planck Institute for

Tax Law and Public Finance

Department of Business and Tax Law

Department of Public Economics

http:/ / www.tax.mpg.de 
Working papers of the Max Planck Institute for Tax Law and Public Finance Research Paper Series serve to disseminate the research results of work in progress prior to publication to encourage the exchange of ideas and academic debate. Inclusion of a paper in the Research Paper Series does not constitute publication and should not limit publication in any other venue. The preprints published by the Max Planck Institute for Tax Law and Public Finance represent the views of the respective author(s) and not of the Institute as a whole. Copyright remains with the author(s).

Max Planck Institute for Tax Law and Public Finance

Marstallplatz 1

D-80539 Munich

Tel: $\quad+498924246-0$

Fax: $\quad+498924246-501$

E-mail:ssrn@tax.mpg.de

http://www.tax.mpg.de 


\title{
To deter or to moderate? Alliance formation in contests with incomplete information
}

\author{
Kai A. Konrad* Florian Morath ${ }^{\dagger}$
}

December 9, 2015

\begin{abstract}
We consider two players' choice about the formation of an alliance ahead of conflict in a framework with incomplete information about the strength of co-players. When deciding on alliance formation, players anticipate the self-selection of other players and the informational value of own and other players' choices. In the absence of these signaling effects, strong players have an incentive to stand alone, which leads to a separating equilibrium. This separating equilibrium can be destabilized by deception incentives if beliefs are updated on the basis of endogenous alliance formation choices. Weak players may find it attractive to appear strong in order to deter competitors from positive effort choices. Strong players may find it attractive to appear weak in order to give their competitors a false sense of security and then beat them with little effort. Moreover, appearing weak allows players to free-ride when alliances are formed.
\end{abstract}

Keywords: alliance; incomplete information; endogenous formation; all-pay contest

JEL Classification: D72, D74

* Corresponding author. Address: Kai A. Konrad, Max Planck Institute for Tax Law and Public Finance, Marstallplatz 1, 80539 Munich, Germany. E-mail: kai.konrad@tax.mpg.de.

${ }^{\dagger}$ Max Planck Institute for Tax Law and Public Finance, Marstallplatz 1, 80539 Munich, Germany. E-mail: florian.morath@tax.mpg.de. 


\section{Introduction}

When players face a conflict and two players can form an alliance with each other, they have to consider what a potential coalition partner is able and willing to contribute to this alliance, and how this affects other players who are not members of the alliance. The players are typically not perfectly symmetric and homogeneous, and their characteristics such as their intentions, their ability or their motivation are often not common knowledge. A motivated and powerful player who may have the opportunity to form an alliance with a weak partner may think about this option differently to a powerless or poorly motivated player who considers the opportunity to join a top team. Often the decisions as to whether to form an alliance must be made under incomplete information on the strength or motivation of other players. In addition to the incentive effects mentioned, two-sided incomplete information adds a further aspect: When the formation of an alliance is a negotiation process, players' behavior in this negotiation may potentially reveal information about a potential alliance partner's characteristics. Players need to take this aspect into consideration, which may affect both the interaction between members of an alliance and the interaction with players outside the alliance.

We provide a microeconomic analysis of alliances in contests in a framework with heterogeneous players and incomplete information about players' strength, if the alliance is the outcome of mutual agreement of its members. Natural examples can be found in a wide spectrum of applications ranging from possible joint ventures in $R \& D$ competition to pre-election commitment of candidates or parties in political competition with plurality voting, or international conflict. The specifics of the particular conflict in many of these problems provide clear a priori constraints about who may form a coalition/alliance with whom. ${ }^{1}$ This consideration makes it seemingly legitimate to side-step a problem that received much attention in the theoretical literature and emerges if a set of $\mathrm{n}$ players can form arbitrary alliances which may be arbitrarily composed of the different players. ${ }^{2}$ It reduces the problem to a decision making

\footnotetext{
${ }^{1}$ The starting point of the rivalry analysis by Thompson (2001) is that not all actors are equally likely to clash. A historical process may determine which pair of states sustain a hostile relationship. Similarly, an alliance between some actors may be more likely than between others.

${ }^{2}$ Coalition formation in a set-up with arbitrary coalitions between a larger number of players generates interesting, but difficult conceptual issues. Hart and Kurz (1983) were among the first to highlight these conceptual issues, particularly the issue of coalition stability. See also Ray and Vohra (1997), Konishi and Ray (2003), and Ray and Vohra (2015) for more recent contributions.
} 
problem whether specific players would like to form an alliance or not. In turn, this allows us to highlight the role of information about players' strength. From a formal perspective our analysis borrows the a-priori feasibility constraint from the generic framework of Esteban and Sákovics (2003) with three players, in which two specific players may be in an alliance or not. We endogenize the choice of these two players whether to form an alliance, and, compared to the theory considerations in Herbst et al. (2015), we allow for, and focus on incomplete information. For describing the possible conflict, we use the theory of all-pay contests as developed by Hillman and Riley (1989), Baye et al. (1996) and Siegel (2009) as the main tool. ${ }^{3}$ This theory defines the basic rules of a conflict game in which players compete for a valuable resource by expending non-recoverable efforts, and for which the set of effort choices translates deterministically in an allocation of the prize.

Experimental evidence suggests that information aspects and players' heterogeneity matter for alliance formation decisions and contest behavior. Under controlled laboratory conditions, human players seemingly differ in their motivation to expend effort in a contest for a given and uniform monetary prize. As shown by Herbst et al. (2015) these expenditure attitudes are correlated with the players' choices on whether to join an alliance: Players who expend relatively little effort are more willing to join an alliance than players who expend much effort. Our framework here analyses these selection effects theoretically, explicitly accounting for incomplete information. It allows for a clear distinction between pure selection effects and information transmission effects of alliance formation decisions.

In a first approach we isolate pure selection effects: Players who differ in their motivation to expend effort make their choices about alliance formation, but can safely disregard the informational value of the offers they make in these negotiations. In a first approach we assume that the players' motivation becomes fully revealed to all players once the alliance formation stage is completed. While this is a less plausible assumption, it allows us to isolate the selection effects. Negotiation offers may be informative, but the information has no additional value given that all information

\footnotetext{
This question is, however, orthogonal to the issue addressed in our paper.

${ }^{3}$ The decisive nature of small differences in contestants' efforts in the all-pay contest has sometimes been criticized on plausibility grounds. However, the robustness of this structure toward contests with some, but small noise has been shown by Alcalde and Dahm (2010) who find that this much larger class of contests has equilibria that are payoff equivalent to those of the all-pay contest.
} 
asymmetries are removed at a later stage of the game. We find strong selection effects and separating equilibria in which strongly motivated players stand alone, whereas poorly motivated players have a preference to form an alliance.

In a second step we change the framework such that alliance formation choices have informational value. We remove the mechanism by which all information is exogenously revealed at the contest stage. Considerations about potential information revelation in the negotiations for alliance formation become relevant and weaken the selection findings. The parameter range shrinks in which the separating equilibrium exists. This change is due to effects that generate mimicking incentives for both the strong players and the poorly motivated players. Poorly motivated players have an incentive to appear strong in order to discourage competitors from risking an attack. But also strong players may find it attractive to mimic poorly motivated players and to take by surprise the competitors who underestimate the strength of their rival and think they are fighting an easy target. Moreover, when entering into an alliance, appearing weak reduces the own burden of contributing.

This work is related to the literature on the role of alliances in conflict in economics more generally, surveyed by Konrad (2014), and in biology, surveyed by Bissonette et al. (2015). The seminal paper at the interface between economics and political science is Olson and Zeckhauser (1966). This paper and much of the literature it has inspired focuses on the disadvantages of free-riding in alliances. ${ }^{4}$ We adopt the key assumptions of this literature: Members of an alliance choose their individual contributions to alliance effort individually and non-cooperatively, but these contributions add up to aggregate resources in a contest with an outside adversary. A seminal paper on the advantages of alliance formation is Skaperdas (1998). He considers a complete information framework and concludes that, due to the free-riding incentives they generate, alliances are not formed unless the technological advantages of fighting in an alliance are sufficiently large. We do not assume such technological advantages. ${ }^{5}$ We also do not consider other potential synergies (as in Kovenock and Roberson 2012 or Konrad and Kovenock 2009). We show, however,

\footnotetext{
${ }^{4}$ This argument strongly draws on the theory of private provision of public goods as analyzed by Bergstrom et al. (1986), Nitzan (1991), Davis and Reilly (1999), and Esteban and Ray (2001).

${ }^{5}$ Sub- or supermodularity of the alliance members' efforts are interesting and relevant aspects of alliances, but these aspects are orthogonal to the informational aspects we study. Supermodularity and effort complementarity plays an important role in the literature on R\&D competition (see Vives 2005 for an overview).
} 
that an alliance may be formed even in the absence of such synergies. One reason we identify is that the formation of an alliance causes a common pool problem and makes its members to reduce their efforts (free riding), which, in turn makes the outside competitor moderate his effort. The benefits of this moderation can exceed the disadvantages from the common pool problem.

The effect of strategic effort moderation is reminiscent of different types of strategic commitment by which players restrain their future contest effort in order to moderate competitors' effort, as found by Kolmar and Wagener (2013) in the context of the Tullock (1980) lottery contest. In their framework the strategic commitment toward moderation is obtained from choosing intra-group incentives to free-ride; such commitment may be useful because it can moderate the competitive behavior of rival groups. They also discuss related contexts in which strategic moderation occurs: Stackelberg leadership (Baik and Shogren 1992) and strategic delegation (Konrad et al. 2004). We focus on ex ante heterogeneous players and aspects of incomplete information in the context of the all-pay contest. In our framework, the formation of an alliance is endogenous and hinges on players' types, which are private information. ${ }^{6}$ The alliance may bring about strategic benefits from moderation, but these are asymmetrically distributed between weak and strong players. We also identify a strategic incentive of weak players which is contrary to moderation: Weak players may attempt to appear strong in order to deter other players from entering into a competition.

Our paper is also related to the literature on all-pay contests under incomplete information. ${ }^{7}$ Typically this literature does not consider the role of alliances. Recent exceptions are Konrad (2012) and Malueg and Zhang (2015). Both papers consider 'information alliances,' that is, all-pay contests in which a subset of players can exchange their private information prior to the contest (where, then, each player competes on his own). They show that sharing information among a subset of players can make these players strictly better off; the out-group may benefit or lose from

\footnotetext{
${ }^{6}$ The experiment by Herbst et al. (2015) also offer a theoretical analysis of the Tullock (1980) lottery contest that corresponds to their experimental setup, assuming, however, that all decisions are made under perfect and complete information.

${ }^{7}$ Standard references are Weber (1985), Hillman and Riley (1989), and Amann and Leininger (1996). For models of imperfectly discriminating contests with incomplete information see, for instance, Hurley and Shogren (1998), Malueg and Yates (2004), and Wasser (2013). Recent work by Kovenock, Morath and Münster (2015) and Serena (2015) considers incentives to inform other contestants about the valuations of winning in incomplete information all-pay contests.
} 
such information sharing agreements. A main difference between Malueg and Zhang (2015) and Konrad (2012) is that the latter focuses on contestants which highly constrained budgets. The idea of information alliances is also closely related to our analysis in Section 3 which includes the case in which alliance formation additionally involves information exchange among alliance players.

Most of the literature on alliances in contests focuses on exogenously formed alliances and compares contest outcomes with or without an alliance. We make the formation decision an endogenous choice. This is an important difference, as the alliance formation choice materially depends on the distribution of types in the population and is an equilibrium outcome, not a comparative static comparison between two exogenously given situations. Since players self-select when making this choice, the composition of types inside the alliance is a result of this endogeneity.

\section{The formal analysis}

\subsection{The model framework}

Consider a contest with three players $A, B$, and $C$. The three players compete for one given prize in an all-pay contest. Player $C$ is a stand-alone player. Players $A$ and $B$ may stand alone but also have the option to form an alliance at a stage which precedes the contest stage. More precisely, Stage 1 is the coalition formation stage in which players $A$ and $B$ simultaneously choose whether they want to enter into an alliance. The alliance formation choice of player $i \in\{A, B\}$ is denoted by $\lambda_{i} \in\{1,0\}$, where $\lambda_{i}=1$ means that $i$ opts favorably for the formation of the alliance and $\lambda_{i}=0$ means that $i$ opts against alliance formation. Once the choices $\lambda_{A}$ and $\lambda_{B}$ are made, they become common knowledge and the alliance formation process is completed. The alliance is formed if $\lambda_{A}=\lambda_{B}=1$ and it is not formed otherwise, that is, the alliance is formed if and only if both players $A$ and $B$ want to enter into an alliance. Otherwise, all three players stand alone.

Now players enter into Stage 2, which is the contest stage. Players compete in an all-pay contest without noise. Each player $i \in\{A, B, C\}$ chooses a non-negative effort denoted by $x_{i} \geq 0$. Choices are made simultaneously and independently. Note that we assume that none of the players is constrained by some finite budget or highest 
possible effort. ${ }^{8}$ The efforts, together with the outcome of the alliance formation stage, determine the players' payoffs.

The contest is about a prize to be attributed to one of the players, but players can have different valuations of the prize. Player $C^{\prime}$ 's prize valuation is $V_{C}=M$ and is common knowledge. The prize valuation $V_{i}$ of player $i \in\{A, B\}$ is drawn from the set $\{H, L\}$ with probabilities

$$
\operatorname{Pr}\left(V_{i}=H\right)=q \text { and } \operatorname{Pr}\left(V_{i}=L\right)=1-q, \quad i=A, B,
$$

where $q \in(0,1)$. This probability distribution is the same for $V_{A}$ and $V_{B}$ and is common knowledge. At the beginning of Stage $1, V_{A}$ and $V_{B}$ are drawn independently from this distribution; player $i \in\{A, B\}$ privately learns his valuation $V_{i}$. At the beginning of stage 2 , and prior to players' contest effort choices, the true valuations $V_{A}$ and $V_{B}$ also become common knowledge. ${ }^{9}$ The most interesting case to consider is the case where ${ }^{10}$

$$
0<L<M<H \text {. }
$$

In Stage 2, if no alliance is formed then $A, B$ and $C$ compete in a standard three-player all-pay contest, and their efforts decide who wins. The expected payoff of player $i \in\{A, B, C\}$ is given by

$$
\pi_{i}\left(x_{A}, x_{B}, x_{C}\right)=\left\{\begin{aligned}
V_{i}-x_{i} & \text { if } x_{i}>x_{j} \text { for all } j \neq i \\
\frac{V_{i}}{k}-x_{i} & \text { if } i \text { ties for the highest effort with } k-1 \text { others, } \\
-x_{i} & \text { if } x_{i}<\max \left\{x_{A}, x_{B}, x_{C}\right\}
\end{aligned}\right.
$$

Hence, the player with the highest effort wins the prize; all others lose. If several players choose the same highest effort, the winner is determined as an outcome of a symmetric lottery between the players expending the same, highest effort. Independent of winning or losing, each player $i$ incurs a cost of effort which is normalized to the effort itself.

\footnotetext{
${ }^{8}$ This rules out that tight budgets and the desire to overcome a liquidity problem by single players is the motivation for alliance formation. Konrad and Kovenock (2009) consider the case with tight effort budgets, in which alliance formation may have the purpose of overcoming the too-tight budget constraints of single players.

${ }^{9}$ This assumption will be relaxed in Section 3.

${ }^{10}$ As will become clear below, alliance formation is always beneficial if $M>H$ (since players $A$ and $B$ get zero expected payoffs if no alliance is formed). The case of $M<L$ requires additional case distinctions but can be analyzed analogously to the subsequent analysis of this section and yields similar conclusions.
} 
If an alliance is formed then the efforts of players $A$ and $B$ add to the alliance effort: $x_{A}+x_{B}$. This additivity is common in the literature on the voluntary provision of public goods more generally. ${ }^{11}$ Additivity of efforts is assumed here to isolate the strategic aspects of alliance formation from possible technological effects. ${ }^{12}$ In the contest the alliance effort $x_{A}+x_{B}$ is compared with the effort $x_{C}$. Expected payoffs are

$$
\begin{aligned}
\pi_{i}\left(x_{A}, x_{B}, x_{C}\right)=\left\{\begin{aligned}
\frac{V_{i}}{2}-x_{i} & \text { if } x_{A}+x_{B}>x_{C}, \\
\frac{V_{i}}{4}-x_{i} & \text { if } x_{A}+x_{B}=x_{C}, \\
-x_{i} & \text { if } x_{A}+x_{B}<x_{C},
\end{aligned} \quad\right. \text { i=A,B, } \\
\pi_{C}\left(x_{A}, x_{B}, x_{C}\right)=\left\{\begin{aligned}
-x_{i} & \text { if } x_{A}+x_{B}>x_{C}, \\
\frac{V_{C}}{2}-x_{i} & \text { if } x_{A}+x_{B}=x_{C}, \\
V_{C}-x_{i} & \text { if } x_{A}+x_{B}<x_{C} .
\end{aligned}\right.
\end{aligned}
$$

Player $C$ wins if $x_{C}>x_{A}+x_{B}$. The alliance wins if $x_{A}+x_{B}>x_{C}$, in which case the prize is allocated either to $A$ or $B$ with equal probability. Should $x_{A}+x_{B}=x_{C}$, then victory is attributed to players $A$ and $B$ each with probability $1 / 4$ and to player $C$ with probability $1 / 2$. The specific tie-breaking probability choices are convenient but not crucial for the results.

We now solve the game recursively. At Stage 2 the true valuations are common knowledge. The players participate in what can be considered a standard all-pay contest with complete information. If $A$ and $B$ have not formed an alliance, Stage 2 is a three-player all-pay contest with linear effort costs and with prize valuations $\left(V_{A}, V_{B}, V_{C}\right)$. If $A$ and $B$ entered into an alliance and compete jointly against $C$, this contest structure is also well-known from the literature. We need to distinguish between these two possible continuation games.

\subsection{The equilibrium in the continuation games}

The continuation game without an alliance has an equilibrium that is known from the literature on the all-pay auction, as characterized by Baye et al. (1996). The equilib-

\footnotetext{
${ }^{11}$ For standard models see Bergstrom et al. (1986), Nitzan (1991), and Davis and Reilly (1999). Additionality of efforts also maps the basic setup of Olson and Zeckhauser (1966) and the more formal work on competing alliances (e.g., Esteban and Ray 2001; Esteban and Sákovics 2003).

${ }^{12}$ Some of the literature assumes supermodularity (Skaperdas 1998). Another part of the literature assumes partial redundancy as in the best-shot models of voluntary contributions to a group public good (Hirshleifer 1983).
} 


\begin{tabular}{ccccc} 
& & $E\left(\pi_{A}\right)$ & $E\left(\pi_{B}\right)$ & $E\left(\pi_{C}\right)$ \\
\hline \hline$V_{A}=L$ & $V_{B}=L$ & 0 & 0 & $M-L$ \\
\hline$V_{A}=L$ & $V_{B}=H$ & 0 & $H-M$ & 0 \\
\hline$V_{A}=H$ & $V_{B}=L$ & $H-M$ & 0 & 0 \\
\hline$V_{A}=H$ & $V_{B}=H$ & 0 & 0 & 0 \\
\hline \hline
\end{tabular}

Table 1: Expected payoffs of players $A, B$, and $C$ in the three-player stand-alone allpay auction, as a function of the valuations of $A$ and $B$, assuming that the valuation of $C$ is $V_{C}=M$.

rium efforts and payoffs depend on the combinations of $V_{A}$ and $V_{B}$. The equilibrium is in mixed strategies in which non-active players choose zero effort and active players randomize on the equilibrium support. This equilibrium solution is well-known and we focus on the payoffs. ${ }^{13}$ While there is a multiplicity in the equilibrium mixed strategies for $V_{A}=V_{B}=L<V_{C}$, all equilibria lead to the same expected payoffs. Using the results in Baye et al. (1996, Theorems 1 and 2) we obtain the unique equilibrium expected payoffs for the different prize valuations as summarized in Table 1.

In the equilibrium the player with the highest valuation receives a payoff equal to the difference between his valuation and the second-highest valuation. All other players receive zero. Intuitively, the player with the highest valuation can guarantee this payoff to himself by bidding marginally above the second-highest valuation. While the equilibrium is not in pure strategies, this argument already explains why the payoff cannot be lower than the difference between the two highest valuations.

We turn next to the situation with coalition formation. If an alliance is formed then the members of the coalition jointly contribute to the total alliance effort $x_{A}+$ $x_{B}$, which is a common good for the alliance. Each alliance player $i$ has a benefit of $V_{i} / 2$ in expectation if the alliance wins. In the appendix, we characterize an

\footnotetext{
${ }^{13}$ For an early treatment see Hillman and Riley (1989). The first full characterization and discussion of existence and uniqueness is in Baye et al. (1996). The concept has been extended along many dimensions, including heterogeneity of both prize valuation and contribution cost functions (Siegel 2009), incumbency advantages (Konrad 2002; Meirowitz 2008) and various cost externalities (Baye et al. 2012).
} 


\begin{tabular}{llccc} 
& & $E\left(\pi_{A}\right)$ & $E\left(\pi_{B}\right)$ & $E\left(\pi_{C}\right)$ \\
\hline \hline$V_{A}=L$ & $V_{B}=L$ & $\frac{1}{16} \frac{L^{2}}{M}$ & $\frac{1}{16} \frac{L^{2}}{M}$ & $M-\frac{L}{2}$ \\
\hline$V_{A}=L$ & $V_{B}=H \leq 2 M$ & $\frac{1}{8} \frac{H L}{M}$ & 0 & $M-\frac{H}{2}$ \\
$V_{A}=L$ & $V_{B}=H>2 M$ & $\frac{H-M}{H} \frac{L}{2}$ & $\frac{H}{2}-M$ & 0 \\
\hline$V_{A}=H \leq 2 M$ & $V_{B}=L$ & 0 & $\frac{1}{8} \frac{H L}{M}$ & $M-\frac{H}{2}$ \\
$V_{A}=H>2 M$ & $V_{B}=L$ & $\frac{H}{2}-M$ & $\frac{H-M}{H} \frac{L}{2}$ & 0 \\
\hline$V_{A}=H \leq 2 M$ & $V_{B}=H \leq 2 M$ & $\frac{1}{16} \frac{H^{2}}{M}$ & $\frac{1}{16} \frac{H^{2}}{M}$ & $M-\frac{H}{2}$ \\
$V_{A}=H>2 M$ & $V_{B}=H>2 M$ & $\frac{1}{2} H-\frac{3}{4} M$ & $\frac{1}{2} H-\frac{3}{4} M$ & 0 \\
\hline \hline
\end{tabular}

Table 2: Expected payoffs of players $A, B$, and $C$ if $A$ and $B$ are in an alliance and $C$ is a stand-alone player, as a function of the valuations of $A$ and $B$, assuming that the valuation of $C$ is $V_{C}=M$.

equilibrium of the contest between an alliance of $A$ and $B$ on one side and the stand-alone player $C$ on the other, and we show that the following result holds:

Proposition 1 Suppose that players $A$ and $B$ form an alliance and have valuations for the prize equal to $V_{A}$ and $V_{B}$, respectively. Then, the symmetric equilibrium payoffs of the continuation game in Stage 2 are as summarized in Table 2.

A proof of Proposition 1 is in the appendix. The payoffs in the continuation games are only instrumental for the main Proposition 2 and follow from conventional reasoning using the theory of the all-pay contest. There are several cornerstones of the analysis that lead to these results. First, the alliance players' valuation of winning is reduced to one half of their respective full valuation of the prize, as the prize is divided between the alliance members if the alliance wins. Second, we make extensive use of the result that if $V_{A}<B_{B}$, for instance, alliance member $A$ prefers to make no contribution to the alliance effort (i.e., $x_{A}=0$ ), given the effort choices by $C$ which are a necessary condition for equilibrium. This simplifies the equilibrium of the remaining contest to the equilibrium of a standard all-pay contest with two players and prize valuations $V_{B} / 2$ and $V_{C}$. Third, if $V_{A}=V_{B}$, we assume symmetry in the expected payoffs of players $A$ and $B$. Here, the standard logic of the all-pay contest determines only the effort choice by $C$ and the sum of efforts chosen by $A$ 
and $B$; there remains, however, discretion about how the two players divide this alliance effort between them. ${ }^{14}$ Therefore, if $V_{A}=V_{B}$, we assume that $A$ and $B$ randomize who is in the active role and who is in the passive role. The active player then competes with $C$ and the passive player chooses zero effort (and prefers to do so, given the other players' equilibrium strategies). Assuming that both players $A$ and $B$ are in the active role with probability $1 / 2$, this leads to symmetric expected payoffs for $A$ and $B$ in case of $V_{A}=V_{B} \cdot{ }^{15}$ For a further and more detailed discussion of this choice see Appendix A.1.

One of the surprising insights from the payoffs summarized in Table 2 is that alliance players do well compared to stand-alone play (see Table 1). Even when $V_{A}=V_{B}=L<V_{C}$, and even though this generates a free-rider problem inside the alliance, the members of the alliance achieve a positive expected payoff. The intuition behind this result is that players benefit from the possibility to free-ride within the alliance. If $V_{A}=V_{B}=L$ then one of the players becomes the active player and gets an expected payoff of zero in equilibrium. The other, passive player, however, can free-ride and enjoys a windfall; the passive player $j$ 's expected payoff is $V_{j} / 2$, multiplied by the probability that the active alliance player will win against player $C$. Note that the formation of an alliance comes with a reduction in the efforts of $A$ and $B$, which is complemented by a reduction in the expected effort by the stand-alone player $C$. This strategic effect benefits players $A$ and $B$, even for $V_{A}=V_{B}=L<V_{C}{ }^{16}$

\footnotetext{
${ }^{14}$ The efforts $x_{A}$ and $x_{B}$ are contributions to a public good for the members of the alliance. With linear payoffs and identical marginal contribution costs and valuations, the logic of Nitzan (1991) applies, making any composition of non-negative contributions to a total equilibrium amount $\left(x_{A}+x_{B}\right)$ an equilibrium composition. Hence, while the total expected alliance payoffs are the same under all compositions $x_{A}+x_{B}$, there is much freedom in how $A$ and $B$ contribute to this total effort, or, more precisely, generate the distribution function of $x_{A}+x_{B}$ (as this sum will not be deterministic in equilibrium).

${ }^{15}$ Note that the nature of the equilibrium with one active and one passive player is also obtained as the limit of the case of $V_{A}<V_{B}$ when $V_{A} \rightarrow V_{B}$ (and vice-versa). Alternatively, $A$ and $B$ may contribute symmetrically to $x_{A}+x_{B}$ in case of $V_{A}=V_{B}$, using a coordination mechanism that has been described in more detail in Konrad and Leininger (2011).

${ }^{16}$ The result is reminiscent of what has been found in the context of strategic delegation in the all-pay contest by Konrad et al. (2004). They showed that symmetric players may delegate their right to take part in an all-pay contest, such that one player chooses a delegate with a very high valuation, but the other player delegates to a delegate whose valuation is much lower than the player's actual valuation. Hiring a delegate causes credible bid-shading, which, in turn, causes a
} 
But players can also lose when forming an alliance, compared to the three-player stand-alone all-pay contest. Whether they gain or lose depends on their own valuation of winning relative to the valuation of the other alliance member, and on the valuation of the stronger alliance player compared to the valuation of the stand-alone player $C$. While weak players (with $V_{i}=L$ ) always gain in expectation from the formation of the alliance, strong players (with $V_{i}=H$ ) lose when forming an alliance with a weak player, compared to stand-alone play. But strong players tend to gain when forming an alliance with another strong player. Therefore, under incomplete information about the co-player's type, this causes players' self-selection to depend on the anticipated self-selection of other players. Before turning to this question, note that the stand-alone player $C$ generally benefits from the formation of the alliance: His expected payoff (weakly) increases compared to no alliance formation since the alliance players' incentives to win are weakened.

\subsection{Alliance formation decisions}

When $A$ and $B$ decide whether they are willing to enter into an alliance $\left(\lambda_{i}=1\right)$ or not $\left(\lambda_{i}=0\right)$, they anticipate the contest outcomes that emerge in the continuation games for all possible combinations of prize valuations. They also anticipate that an alliance is formed if and only if both players opt for it, that is, $\left(\lambda_{A}, \lambda_{B}\right)=(1,1)$. When deciding on alliance formation, player $i \in\{A, B\}$ knows his own valuation $V_{i}$ and the probability distribution of the valuation of $j \in\{A, B\}, j \neq i$, that is, $i$ knows that $V_{j}=H$ with probability $q$ and $V_{j}=L$ with probability $1-q$. The players also know that the true prize valuations of all players will become common knowledge once players enter into the contest stage. ${ }^{17}$ We state the equilibrium choices in the next proposition that is the first main result:

Proposition 2 For the equilibrium continuation payoffs characterized in Tables 1 and 2, the following choices characterize perfect Bayesian equilibrium behavior in

reduction in the competitor's effort choice; the overall effect is beneficial for the player who hires the delegate with a low valuation.

${ }^{17}$ The complete information assumption about the contest stage is important. It avoids all the complications emerging from how the alliance formation choices are interpreted by the different players, in particular, how the choices affect players' beliefs about other players' true valuations of the prize. The common knowledge assumption in Stage 2 makes the second stage of the game straightforward and it separates self-selection effects from signaling aspects. 
Stage 1:

(i) Equilibrium type 1: Players $i \in\{A, B\}$ choose $\lambda_{i}=1$ if $V_{i}=L$ and $\lambda_{i}=0$ if $V_{i}=H$.

(ii) Equilibrium type 2: Players $i \in\{A, B\}$ choose $\lambda_{i}=1$. For $H \leq 2 M$, this equilibrium exists if

$$
q \frac{1}{16} \frac{H^{2}}{M} \geq(1-q)(H-M)
$$

for $H>2 M$, this equilibrium exists if

$$
q\left(\frac{1}{2} H-\frac{3}{4} M\right) \geq(1-q) \frac{H}{2} .
$$

Proof. Part (i): Consider first player $i$ with $V_{i}=L$. In the candidate equilibrium, $i$ correctly anticipates that $\lambda_{j}=1$ if $V_{j}=L$ and $\lambda_{j}=0$ if $V_{j}=H$. If $\lambda_{i}=1$, an alliance is formed with probability $1-q$ (that is, if $V_{j}=L$ ) and a stand-alone contest emerges with probability $q$. Since the players' types are revealed at the contest stage, deviations in stage 1 only affect the choice of the continuation game but do not influence the contest payoffs in the respective continuation games. Thus, using Tables 1 and 2, $i$ 's expected payoff in the candidate equilibrium is strictly positive, but $i$ gets zero when deviating to $\lambda_{i}=0$ in which case a stand-alone contest emerges with probability one.

Consider next player $i$ with $V_{i}=H$. Since $\lambda_{i}=0$ triggers a stand-alone contest, $i$ 's expected payoff in the candidate equilibrium is zero if $V_{j}=H$ and is equal to $H-M$ if $V_{j}=L$ (compare Table 1 ). If $i$ deviates to $\lambda_{i}=1$, he correctly anticipates that this deviation becomes relevant if and only if $V_{j}=L$. Thus, he still gets zero if $V_{j}=H$ (in the subsequent stand-alone contest) and gets $\max \{H / 2-M, 0\}$ if $V_{j}=L$, in which case an alliance is formed. Comparing the expected payoffs under $\lambda_{i}=0$ and $\lambda_{i}=1$ shows that $i$ strictly prefers $\lambda_{i}=0$ if $V_{i}=H$. Altogether, this yields the "type-1" equilibrium which is supported by equilibrium beliefs that $\lambda_{j}=1$ if $V_{j}=L$ and $\lambda_{j}=0$ if $V_{j}=H$.

Part (ii): Since players $i$ with $V_{i}=L$ get zero payoff in the stand-alone contest but a strictly positive expected payoff when an alliance is formed, weak players do not want to deviate from the candidate equilibrium. Hence, consider a strong player with $V_{i}=H$ and consider first the case of $H \leq 2 M$. In the candidate equilibrium, $i$ correctly anticipates that an alliance is formed with probability one, which yields 
an expected payoff equal to

$$
q \frac{1}{16} \frac{H^{2}}{M}+(1-q) 0
$$

since $V_{j}=H$ with probability $q$ and $V_{j}=L$ with probability $1-q$. If $i$ deviates to $\lambda_{i}=0$, a stand-alone contest emerges (independent of $\lambda_{j}$ ) in which $i$ 's expected payoff is equal to

$$
q 0+(1-q)(H-M)
$$

(compare Table 1). ${ }^{18}$ Thus, $i$ does not want to deviate from the candidate equilibrium if and only if (1) holds.

Now consider the choice of player $i$ with $V_{i}=H$ in case of $H>2 M$. In the candidate equilibrium, $i$ 's expected payoff is

$$
q\left(\frac{1}{2} H-\frac{3}{4} M\right)+(1-q)\left(\frac{H}{2}-M\right) .
$$

If $i$ deviates to $\lambda_{i}=0$, then a stand-alone contest emerges in which $i$ 's expected deviation payoff is again

$$
q 0+(1-q)(H-M)
$$

Thus, $i$ does not want to deviate from $\lambda_{i}=1$ if and only if (2) holds. The "type-2" equilibrium is supported by beliefs that $\lambda_{j}=1$ both for $V_{j}=L$ and for $V_{j}=H$. Note that the conditions (1) and (2) for existence of the type-2 equilibrium are more likely to be fulfilled if $q$ is large.

Proposition 2 characterizes two types of pure-strategy equilibria. These suggest that weak players may like to join an alliance, whereas strong players are more inclined to stand alone. ${ }^{19}$ Strong players may either never join an alliance, even though weak players do (Proposition 2(i)), or they may like to join an alliance, but only if additional conditions are fulfilled (Proposition 2(ii)). ${ }^{20}$ This result is in line

\footnotetext{
${ }^{18}$ Note that $j$ 's off-equilibrium beliefs following a deviation of $i$ are irrelevant for whether a deviation is profitable since all players' valuations become common knowledge at the contest stage.

${ }^{19}$ Note that there is no equilibrium for which players $i \in\{A, B\}$ choose $\lambda_{i}=0$ if $V_{i}=L$ and $\lambda_{i}=1$ if $V_{i}=H$. These choices contradict the strict dominance of $\lambda_{i}=1$ in case of $V_{i}=L$ if the probability for a $H$-type to choose $\lambda_{i}=1$ is positive.

${ }^{20}$ In addition to the equilibria in Proposition 2, there is a trivial equilibrium in which $i \in\{A, B\}$ chooses $\lambda_{i}=0$ independent of $V_{i}$, as none of the players can affect the alliance formation decision if the other player chooses $\lambda_{j}=0$. This equilibrium is not robust to a number of refinements such as the possibility that players make small mistakes in their choices of $\lambda_{i}$, or that an alliance is formed even for $\left(\lambda_{i}, \lambda_{j}\right)=(1,0)$ with a very small probability.
} 
with the experimental findings by Herbst et al. (2015). ${ }^{21}$

The equilibria in Proposition 2 offer insights into the incentives of players as regards the formation of an alliance. One effect is a direct disincentive effect of alliance formation. Players who enter into an alliance have to "share" the prize of winning (where sharing occurs here in a probabilistic sense). This makes winning less attractive and reduces their general motivation to expend effort. For players with a low valuation this disincentive effect is not a major cost since they already expect zero payoff in the three-player stand-alone contest. In contrast, the disincentive effect is a true disadvantage for a player who is the only player with the highest valuation of the prize. His expected payoff is high in the three-player stand-alone contest (equal to the difference between his and the second-highest prize valuation), but the disincentive from prize-sharing makes this player a much weaker competitor in an alliance and tends to reduce his payoff.

However, there is also a less obvious, beneficial effect from alliance formation: The alliance players are substitutes in making effort contributions. As a consequence, they contribute less effort in expectation and win with lower probability. But anticipating the free-riding problem within the alliance, the stand-alone player $C$ also expends less effort. This strategic effect on $C$ 's effort mitigates the decrease in the alliance's win probability. For weak players, the positive effect of lower effort cost dominates the lower win probability such that the overall effect of alliance formation is always positive. For strong players, the overall effect of alliance formation is positive if and only if the probability that their alliance partner is also a strong type is sufficiently high. In this case, alliance formation helps avoid the fierce competition with other strong players in stand-alone contests, and alliance members enjoy a windfall from a similar effort moderation effect that makes alliance formation the dominant choice for weak players. However, strong players dislike the formation of an alliance with a weak player as the weak player free-rides on them.

Figure 1 illustrates the parameter range in which strong players, under incomplete information on the strength of their possible co-player in the alliance, can be willing to enter into an alliance. For this purpose we set $M=1$ and consider variations of $H$ and $q$. The range in which the equilibrium of "type 2" (Proposition 2(ii)) exists

\footnotetext{
${ }^{21}$ Their paper also offers some theory insights on the three-player structure in the context of a framework with complete information and with the Tullock (1980) lottery contest. Proposition 2 also extends their full information theory results toward a different class of, more discriminatory, contests.
} 


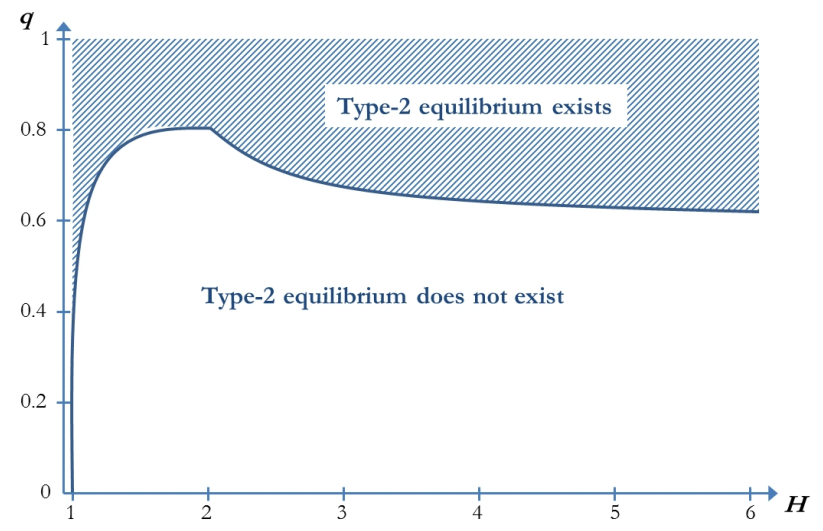

Figure 1: The area above the curve represents the range of combinations $(H, q)$ for which an equilibrium type 2 exists where both weak and strong players choose to form an alliance (setting $M=1$ ).

is the range above this curve.

The free-riding within the alliance can be considered as a commitment to expend lower effort which also makes the stand-alone player $C$ less aggressive. But the existence of the two types of equilibria in Proposition 2 does not qualitatively depend on the assumption that the alliance players will choose their efforts non-cooperatively and thus commit to low efforts. In Section 4 we show that similar results can be obtained in case we assume that an alliance, if formed, maximizes joint expected payoffs $E\left(\pi_{A}\right)+E\left(\pi_{B}\right)$.

\section{Deterrence and Moderation}

The previous section demonstrated the players' motivations to self-select into an alliance or into stand-alone outcomes, basing their choices on expectations of whether the co-players will be strong or weak. Strategic considerations about the information value of alliance formation choices were absent, as players' true types became publicly observable at a later stage. This section focuses on the self-selection of strong and weak players if incomplete information in Stage 2 leads to strategic considerations about the informational value of alliance formation offers. In this case, players need to update their prior beliefs about their co-players' types on the basis of their alliance 
choices and may compete in Stage 2 in a contest with (at least partially) incomplete information about other players' types.

We consider a game that differs from the previously studied game in exactly one important aspect: There is no exogenous information revelation between Stage 1 and Stage 2. Even though the distinction is not very substantial for the qualitative results, for the formal analysis we need to distinguish between two cases. One case has an information exchange inside the alliance. More formally, players $A$ and $B$ can observe each other's type if and only if $\lambda_{A}=\lambda_{B}=1 .^{22}$ The second case has no such intra-alliance information exchange. Players may update their beliefs about $A$ and $B$ 's type, but incomplete information remains even between the members of an alliance if an alliance is formed. More formally, player $C$ 's valuation is common knowledge, but player $A$ and player $B$ 's valuations are their private information. All three players must form beliefs about the types of players whose valuation is private information, and these beliefs can depend on $\left(\lambda_{A}, \lambda_{B}\right)$.

Equilibrium analysis of the all-pay contest becomes difficult if more than two heterogeneous players are partially informed about each other, and no general solutions for this case exist. ${ }^{23}$ As our main interest is in the question whether strong players may self-select into stand-alone play and whether the insight in Proposition 2 is robust in a framework in which the choices $\left(\lambda_{A}, \lambda_{B}\right)$ influence players' beliefs, we concentrate on the characterization of separating equilibrium with this property. ${ }^{24,25}$

Proposition 3 (i) Suppose that players who are jointly in an alliance can observe each other's valuations. Then there is a perfect Bayesian separating equilibrium in

\footnotetext{
${ }^{22}$ Intra-alliance information exchange is a seemingly natural assumption. Players who form an alliance may mutually learn about their types. In political sciences, Bearce et al. (2006) argue that alliances may serve the purpose of internal information exchange. Similarly, it seems natural to assume that the formation of alliances in other areas such as R\&D joint ventures also increases the information flow between the players who enter into an alliance. Konrad (2012) analyzes the role of information exchange in contests between players with tight budget constraints.

${ }^{23}$ For results in a framework with two players see Amann and Leininger (1996), Konrad (2004), and Morath and Münster (2013).

${ }^{24}$ Note that the "trivial" equilibrium with $\lambda_{A}=\lambda_{B}=0$ continues to exist (since players cannot individually induce the formation of an alliance) but remains unstable. The choice of $\lambda_{i}$ can, however, influence beliefs about players' types; thus, the existence of the "trivial" equilibrium requires appropriate off-equilibrium beliefs.

${ }^{25}$ Note that a perfect Bayesian equilibrium in which $\lambda_{i}=0$ if $V_{i}=L$ and $\lambda_{i}=1$ if $V_{i}=H$ still does not exist in this framework. While the choices of $\left(\lambda_{A}, \lambda_{B}\right)$ would be fully revealing in this candidate equilibrium, weak types would be strictly better off when deviating to alliance formation.
} 
pure strategies in Stage 1 with $\lambda_{i}=0$ if $V_{i}=H$ and $\lambda_{i}=1$ if $V_{i}=L$ if and only if

$$
\frac{H-M}{H} \leq \frac{L}{16 M}
$$

and

$$
(1-q)\left(\frac{H+L}{2}-M\right) \geq q(H-M)
$$

(ii) Suppose that the valuations of players $A$ and $B$ remain private information in Stage 2, whether or not $A$ and $B$ form an alliance. Then there is a perfect Bayesian separating equilibrium in pure strategies in Stage 1 with $\lambda_{i}=0$ if $V_{i}=H$ and $\lambda_{i}=1$ if $V_{i}=L$ if and only if (3) holds and (a) $2 M(H-L)-L H<0$ and (4) holds or (b) $2 M(H-L)-L H \geq 0$ and

$$
(1-q)(H-M) \geq q(H-M)+(1-q)\left(\frac{H-L}{4}+\frac{4 M^{2}(H-L)^{2}+L^{2} H^{2}}{16 L M H}\right) .
$$

Proof. If all players believe that the other player's choice $\lambda_{j}$ is truthful and fully revealing, we need to prove that deviations from the candidate equilibrium are not profitable for the players given these beliefs. First we state as a benchmark the equilibrium expected payoffs of $A$ and $B$ conditional on their valuation. Then we determine deviation payoffs and compare the benchmark payoffs with the deviation payoffs.

Consider the benchmark payoffs in the candidate equilibrium, which are the same for cases $(i)$ and $(i i)$ in Proposition 3. If all players' choices are truthful, all players enter stage 2 as in an all-pay contest with complete information. Suppose first that $V_{i}=H, i \in\{A, B\}$. Then, $\lambda_{i}=0$ and stage 2 is an all-pay contest among three stand-alone players. Here, $i$ 's expected payoff is zero if $\lambda_{j}=0$ (and $V_{j}=H$ ) for $j \in\{A, B\}, j \neq i$. Expected payoff is equal to $H-M$ if $\lambda_{j}=1$ (and $V_{j}=L$ ). Thus, player $i$ 's expected payoff at stage 1 when $\lambda_{j}$ has not yet been chosen is

$$
E\left(\pi_{i} \mid V_{i}=H\right)=(1-q)(H-M)
$$

Along similar lines, if $V_{i}=L$ and $\lambda_{i}=1$, then $i$ 's expected payoff in Stage 1 when $\lambda_{j}$ has not been chosen is

$$
E\left(\pi_{i} \mid V_{i}=L\right)=q \cdot 0+(1-q) \frac{1}{16} \frac{L^{2}}{M} .
$$


Part (i): Suppose that $A$ and $B$ can observe each other's valuation if they are in an alliance.

(a) Let $V_{i}=L$ but $\lambda_{i}=0$. Then a three-player stand-alone contest emerges in which the deviating player $i$ is mistakenly taken by $j$ and $C$ as a player with $V_{i}=H$. The deviating player $i$ 's effort choice $x_{i}$ in this contest depends on the type of player $j$ which is truthfully revealed by $j$ 's choice of $\lambda_{j}$.

(aa) If $\lambda_{j}=0$, then $i$ expects $F_{j}\left(x_{j}\right)=x_{j} / H$ in the equilibrium support $x_{j} \in$ $[0, H]$, and $x_{C} \equiv 0$. Player $i$ 's optimal reply to these effort choices is $x_{i} \equiv 0$, yielding a deviation payoff of zero.

(ab) If $\lambda_{j}=1$, then $i$ expects $x_{j} \equiv 0$ and $F_{C}(x)=(1-M / H+x / H)$ for $x \in[0, M]$. For $x_{i}=0, i$ 's expected payoff depends on the tie-breaking rule since $C$ chooses zero effort with strictly positive probability. For $x_{i}>0$, we get

$$
\frac{d \pi_{i}}{d x_{i}} \leq \frac{1}{H} L-1<0 .
$$

Thus, $i$ would like to choose a minimal amount of effort to win at least with the probability that $x_{C}=0$. To avoid the problem of the non-existence of a best reply function for $i$ in a continuous strategy space, we assume that ties are broken in favor of player $i$ in this case, which yields an optimal deviation effort of $i$ equal to $x_{i}=0$ and an expected deviation payoff equal to $(1-M / H) L .^{26}$

At the point when $\lambda_{j}$ has not been chosen, $i$ 's expected deviation payoff is thus

$$
q \cdot 0+(1-q)\left(1-\frac{M}{H}\right) L .
$$

Comparing (6) and (7) shows that a player $i$ with $V_{i}=L$ does not want to deviate from $\lambda_{i}=1$ if and only if

$$
\frac{L}{16 M} \geq \frac{H-M}{H} .
$$

(b) Let $V_{i}=H$ but $\lambda_{i}=1$. Then $i$ is mistakenly perceived by $C$ as a player with $V_{i}=L$. The belief of $j$ about $i$ depends on whether an alliance is formed, which, again, depends on $\lambda_{j}$.

(ba) If $\lambda_{j}=0$ (and hence $V_{j}=H$ ) then a three-player stand-alone contest emerges. In this contest $i$ correctly expects to compete against one player $j$ with

\footnotetext{
${ }^{26}$ Note that this deviation payoff is the limit of $i$ 's payoff when choosing $x_{i}=\varepsilon>0$ and when $\varepsilon$ approaches zero.
} 
$V_{j}=H$ and one player $C$ with $V_{C}=M$. Players $j$ and $C$ mistakenly think that $V_{i}=L$ and hence expect $x_{i} \equiv 0$; by Baye et al. (1996), the equilibrium mixed strategies of $j$ and $C$ are $F_{j}\left(x_{j}\right)=x_{j} / M$ and $F_{C}\left(x_{C}\right)=1-(M / H)+\left(x_{C} / H\right)$ with equilibrium support $[0, M]$. The best response of the deviating player $i$ to these anticipated choices is $x_{i}=M$ and leads to a payoff of $(H-M)$.

(bb) If instead $\lambda_{j}=1$ (and hence $V_{j}=L$ ) then the alliance is formed. Both $i$ and $j$ learn of each other's type $\left(V_{i}=H, V_{j}=L\right)$. Player $C$ expects to play against an alliance with $V_{A}=V_{B}=L$. The equilibrium that emerges based on these beliefs has $F_{C}\left(x_{C}\right)=x_{C} /(L / 2), x_{j}=0$, and $x_{i}=L / 2$. Since the alliance wins with probability one, $i$ 's payoff is $H / 2-L / 2$. Thus, $i$ 's expected deviation payoff at the point where $\lambda_{j}$ has not yet been chosen is

$$
q(H-M)+(1-q)\left(\frac{H}{2}-\frac{L}{2}\right) .
$$

Comparing (5) and (9) shows that deviations for players $i$ with $V_{i}=H$ are not profitable if and only if

$$
(1-q)\left(\frac{H+L}{2}-M\right) \geq q(H-M) .
$$

Altogether, the separating equilibrium exists for parameters $(H, M, L, q)$ if and only if (3) and (4) hold. This set can be shown to be non-empty, which we do when offering an intuitive interpretation.

Part (ii): Consider now the case without intra-alliance information sharing. Recall that the expected benchmark payoffs in the candidate equilibrium are given by (5) and (6).

(a) Let $V_{i}=L$ but $\lambda_{i}=0$. As no alliance is formed, the expected deviation payoff is as in part (i), case (a). Accordingly, player $i$ with $V_{i}=L$ does not want to deviate from $\lambda_{i}=1$ if and only if (8) holds.

(b) Let $V_{i}=H$ but $\lambda_{i}=1$. Then $i$ is mistakenly perceived by $j$ and $C$ as a player with $V_{i}=L$. Whether or not an alliance forms depends on $\lambda_{j}$, that is, on $V_{j}$.

(ba) If $\lambda_{j}=0$ (and hence $V_{j}=H$ ) then no alliance is formed and the deviation payoff is as in part (i), case (ba) and equal to $(H-M)$.

(bb) If $\lambda_{j}=1$ (and hence $V_{j}=L$ ) then the alliance is formed. Player $i$ correctly expects to be in an alliance with a player with $V_{j}=L$ against player $C$ with $V_{C}=M$. In contrast to part (i), no information transfer inside the alliance takes place and 
both $C$ and $j$ (mistakenly) think that $V_{i}=L$. To describe the equilibrium given these beliefs and true valuations, we follow the equilibrium considerations for a correlated equilibrium inside the alliance as already used for the benchmark payoffs (compare Proposition 1). Player C's equilibrium strategy is $F_{C}\left(x_{C}\right)=x_{C} /(L / 2)$. From the point of view of $j$, the coordination device applies. If $j$ is chosen as the passive player (with probability $1 / 2$ ), $i$ 's best reply to $x_{j}=0$ and $F_{C}$ is $x_{i}=L / 2$, which ensures victory. Hence, conditional on being chosen as the active player, $i$ 's maximized deviation payoff $\hat{\pi}_{i}$ is

$$
\hat{\pi}_{i}(i \text { active })=\frac{H}{2}-\frac{L}{2} .
$$

With the remaining probability $1 / 2$, player $i$ is chosen to be the passive alliance player. The active player $j$ randomizes according to $F_{j}(x)=1-(L / 2) / M+x / M$. We search for player $i$ 's best reply, given that $C$ randomizes according to $F_{C}$ and $j$ randomizes according to $F_{j}(x)$. If $i$ chooses $\check{x}_{i}=0$, the alliance may only win if $x_{j}>0$ and $i$ 's expected deviation payoff $\check{\pi}_{i}$ is

$$
\check{\pi}_{i}\left(\check{x}_{i}=0 \mid i \text { passive }\right)=\int_{x_{j}=0}^{x_{j}=\frac{L}{2}} F_{C}\left(x_{j}\right) d F_{j}\left(x_{j}\right) \frac{H}{2}=\frac{L H}{8 M} .
$$

For $\check{x}_{i} \in\left(0, \frac{L}{2}\right)$, the alliance wins with probability $F_{C}\left(\check{x}_{i}\right)$ if $x_{j}=0$, with probability $F_{C}\left(\check{x}_{i}+x_{j}\right)$ if $0<x_{j}<\frac{L}{2}-\check{x}_{i}$, and with probability one if $x_{j} \geq \frac{L}{2}-\check{x}_{i}$. Thus, the probability that the alliance wins is

$\operatorname{Pr}\left(\right.$ alliance wins; $\left.F_{C}, F_{j} ; x_{i}\right)=F_{j}(0) F_{C}\left(\check{x}_{i}\right)+\int_{0}^{\frac{L}{2}-\check{x}_{i}} F_{C}\left(\check{x}_{i}+x_{j}\right) d F_{j}\left(x_{j}\right)+\left(1-F_{j}\left(\frac{L}{2}-\check{x}_{i}\right)\right)$

and $i$ 's expected deviation payoff for $\check{x}_{i} \in\left(0, \frac{L}{2}\right)$ is given by

$$
\begin{aligned}
\check{\pi}_{i}\left(\check{x}_{i} \mid i \text { passive }\right) & =\operatorname{Pr}\left(\text { alliance wins } ; F_{C}, F_{j} ; x_{i}\right) \frac{H}{2}-\check{x}_{i} \\
& =\frac{\check{x}_{i}}{L} H+\frac{1}{8} \frac{L}{M} H-\frac{1}{2 L M} H\left(\check{x}_{i}\right)^{2}-\check{x}_{i} .
\end{aligned}
$$

Note first that (11) is continuous in $\check{x}_{i}$ and approaches $L H /(8 M)$ for $\check{x}_{i} \rightarrow 0$ and approaches $(H-L) / 2$ for $\check{x}_{i} \rightarrow L / 2$. Moreover, $\check{x}_{i}=L / 2$ is strictly preferred to all $\check{x}_{i}>L / 2$ (since for $\check{x}_{i}=L / 2$ the alliance wins with probability one). Since

$$
\frac{d}{d \check{x}_{i}} \check{\pi}_{i}\left(\check{x}_{i} \mid i \text { passive }\right)=\frac{M(H-L)-H x}{L M},
$$


$i$ will always choose $\check{x}_{i}>0$. Due to strict concavity of $\check{\pi}_{i}$ in $\check{x}_{i}$, the optimal choice is equal to $\check{x}_{i}=L / 2$ if and only if

$$
\frac{d}{d \check{x}_{i}} \check{\pi}_{i}\left(\check{x}_{i}=\frac{L}{2} \mid i \text { passive }\right) \geq 0 \Leftrightarrow 2 M(H-L)-L H \geq 0
$$

Otherwise, the optimal choice is obtained by the first-order condition, which yields $\check{x}_{i}=M(H-L) / H$. Inserting $i$ 's optimal effort choice into (11) yields

$$
E\left(\check{\pi}_{i} \mid i \text { passive }\right)=\left\{\begin{array}{cl}
\frac{H-L}{2} & \text { if } 2 M(H-L)-L H \geq 0, \\
\frac{4 M^{2}(H-L)^{2}+L^{2} H^{2}}{8 L M H} & \text { if } \quad 2 M(H-L)-L H<0 .
\end{array}\right.
$$

Summing up, the expected deviation payoff of $i$ if $V_{i}=H$ is

$$
E\left(\check{\pi}_{i}\right)=\left\{\begin{array}{cl}
q(H-M)+(1-q)\left(\frac{H-L}{4}+\frac{H-L}{4}\right) & \text { if } 2 M(H-L)-L H \geq 0 \\
q(H-M)+(1-q)\left(\frac{H-L}{4}+\frac{4 M^{2}(H-L)^{2}+L^{2} H^{2}}{16 L M H}\right) & \text { if } 2 M(H-L)-L H<0 .
\end{array}\right.
$$

Now we compare $i$ 's payoff in the candidate equilibrium with the expected deviation payoff. If $2 M(H-L)-L H \geq 0$, we find that $E\left(\pi_{i}\right) \geq E\left(\check{\pi}_{i}\right)$ if and only if

$$
(1-q)\left(\frac{H+L}{2}-M\right) \geq q(H-M),
$$

as in (4). If $2 M(H-L)-L H<0$, then $E\left(\pi_{i}\right) \geq E\left(\check{\pi}_{i}\right)$ if and only if

$$
(1-q)(H-M) \geq q(H-M)+(1-q)\left(\frac{H-L}{4}+\frac{4 M^{2}(H-L)^{2}+L^{2} H^{2}}{16 L M H}\right) .
$$

Equilibrium in all-pay contests typically is in mixed strategies, and the equilibrium outcomes in this proposition are no exception. This makes the equilibrium play of two players $A$ and $B$ in a coalition a particular challenge. Their efforts sum up to the alliance effort, and to allocate the prize, this sum needs to be compared with the effort chosen by the outside player $C$. To make this player $C$ indifferent as regards his effort, the sum of efforts by $A$ and $B$ needs to follow a particular distribution. This distribution, in turn, is must be generated from the randomization choices of $A$ and $B$. In the proof of Proposition 3 we solved this conceptual issue and used a simple coordination device of $A$ and $B$ that allows them to determine who expends effort and who does not, and it is not possible to avoid some structural assumption 
at this point. Similar coordination devices have been applied in inter-group all-pay contests by Konrad and Kovenock (2009) and Konrad and Leininger (2011).

We can compare the fully separating self-selection equilibrium in Propositions 2 and 3 , for which $\lambda_{i}=0$ if and only if $V_{i}=H$. This comparison shows that no parameter restrictions are needed for the existence of this equilibrium if the true valuations are exogenously revealed once the alliance formation choices are made and before players enter the all-pay contest (Proposition 2(i)). The range of existence of this equilibrium is more limited if the alliance formation choice carries informational value such that these choices $\lambda_{A}$ and $\lambda_{B}$ are used to update beliefs (Proposition 3). Unlike many incentive problems where only one type aims at mimicking the other type, players with valuations $L$ and $H$ both have an incentive to deceive the other players, which makes the problem non-standard. A weak player may want to appear strong for reasons of deterrence, and a strong player may want to appear weak for reasons of moderation. Even though the game structure and the information assumptions are quite different, these considerations are reminiscent of Fudenberg and Tirole (1984) whose seminal paper studies strategic investment in an entry game. There, players prefer to deter others from entry, but would like to soften competition once entry has occurred. In our framework, a weak player $A$ (with $V_{A}=L$ ) gains by being perceived as a strong player: In the subsequent three-player stand-alone contest, this makes $C$ "exit" (that is, abstain from expending positive effort) with a positive probability; moreover, $B$ also abstains from expending positive effort if $V_{B}=L$. This incentive is larger the larger the ratio between $H$ and $M$, as this ratio determines $C$ 's equilibrium exit probability. A strong player $A$ (with $V_{A}=H$ ) gains when being perceived as a weak player: He benefits from the bid moderation of $C$ that is induced if an alliance with $B$ is formed, and $A$ deceives a strong player $B$ in the case of stand-alone play. In the latter case, $B$ believes that $A$ is weak and bids only a small amount, thinking that this will be enough to win. This, in turn, gives $A$ the opportunity to win against $B$ and $C$ with comparatively little effort.

The deception incentives both for weak and for strong players are quite strong and the conditions in Proposition 3 narrow down the parameter set that describes the existence of the separating equilibrium. However, the parameter set is nonempty. To see this, let $q$ become very small, in which case condition (4) becomes $(H+L) / 2-M \geq 0$. Figure 2 illustrates the separating hyperplanes that determine the parameter range for which the separating equilibrium exists, normalizing $M=1$. For the regime with information exchange inside the alliance (Proposition 3(i)), this 


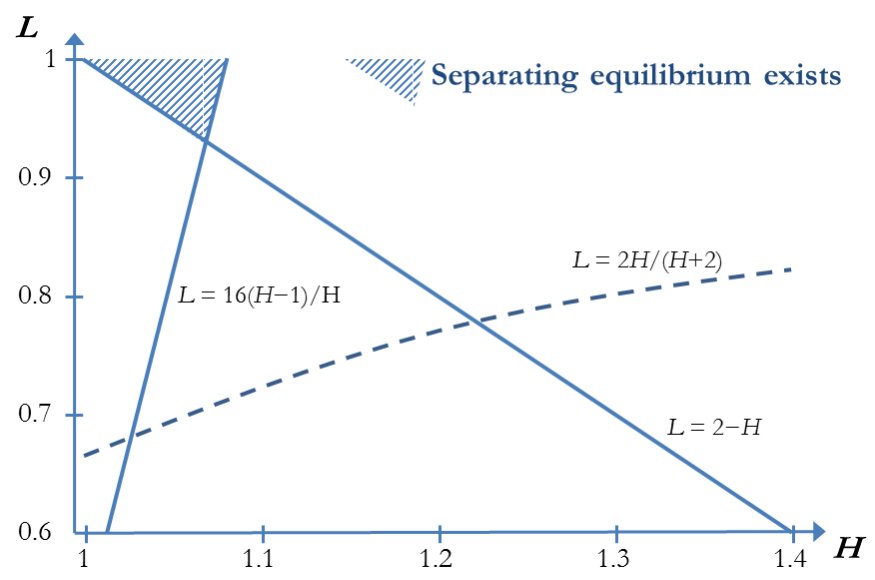

Figure 2: The shaded area represents the range of combinations $(H, L)$ for which the separating equilibrium exists (Proposition 3(i) and (ii) case a), setting $M=1$.

requires, in addition, condition (3) which becomes $L \geq 16(H-1) / H$. For the regime without information exchange inside the alliance (Proposition 3(ii)), (3) and (4) are the relevant conditions in case of $2 M(H-L)-L H<0$; this restriction corresponds to the area above the dashed curve in Figure 2. The upper area in which the separating equilibrium exists is a range in which both $H$ and $L$ are not too different from $M$.

\section{Collusive Alliances}

The main analysis makes a number of assumptions. This section discusses the sensitivity of our results. One important aspect we look at is what is meant by an alliance and how members of an alliance coordinate their efforts.

In the previous sections, an alliance changes the rules about how the prize is awarded, but the interaction remains fully non-cooperative and each player remains an independent strategic decision maker. This assumption about non-cooperative effort contributions is grounded in much of the work on alliances that was inspired by Olson and Zeckhauser (1966). However, alliances may sometimes, and to some extent, succeed in installing a governance structure to overcome free-riding, such that the alliance can act as one strategic player. In this case the alliance chooses 
aggregate alliance effort so as to maximize the collective benefit of the alliance. In addition, such a governance structure must determine the rules by which the prize is allocated inside the alliance, how the aggregate effort is assigned to the alliance members, whether or not alliance members may be able to make side payments and, in our context, what is the information structure inside the alliance and between the alliance and the stand-alone player in case an alliance is formed. This shows that departures from the classical free-riding approach may lead to one of a whole set of different structures.

To see that the results need not change dramatically for such a departure, we study collusive alliances for one set of assumptions. More precisely, we assume as in Section 2 that signaling aspects are absent: The valuations of players $A$ and $B$ (which are private information in Stage 1) become common knowledge at the contest stage. Moreover, just as in the previous sections, we assume that in case the alliance wins, player $A$ and $B$ each receives the prize with probability $1 / 2$, just as in the previous sections. Finally, we assume that the expected payoffs of both $A$ and $B$ are non-negative and that symmetric players (with $V_{A}=V_{B}$ ) contribute symmetrically to alliance effort.

Remark 1 Suppose that if an alliance is formed, players $A$ and $B$ choose their efforts so as to maximize joint expected payoffs. Then the following choices characterize perfect Bayesian equilibrium behavior in Stage 1:

(i) Equilibrium type 1: Players $i \in\{A, B\}$ choose $\lambda_{i}=1$ if $V_{i}=L$ and $\lambda_{i}=0$ if $V_{i}=H$

(ii)Equilibrium type 2: Players $i \in\{A, B\}$ choose $\lambda_{i}=1$ if and only if $q$ is sufficiently high.

Details on Remark 1 are in the appendix. Note that the joint payoff maximization of alliance players does not necessarily increase the total expected payoff of players $A$ and $B$ when forming an alliance. On the contrary, if alliance players are rather weak then the disincentive effect and the free-riding possibilities within the alliance make them achieve a strictly higher payoff than if alliance players "cooperated" and maximized joint payoffs. As in a number of other contexts (e.g., Salant et al. 1983), the transformation of two independent strategic players into one strategic player is not necessarily to the advantage of these players.

More importantly, the qualitative predictions of Proposition 2 are reinforced for collusive alliances. In particular, there is an equilibrium where weak types select into 
alliances and strong types select into stand-alone contests. Moreover, if the share of high types is sufficiently large then there is an additional equilibrium in which players $A$ and $B$ enter into an alliance independently of their respective type. ${ }^{27}$ This suggests that the intuition about particularly strong players being better-off standing alone is a more robust result that emerges for several sets of assumptions that can be made in the context of alliance formation.

\section{Conclusions}

A strong intuition suggests that relative strength matters for players who are considering whether to form an alliance. Weak players may expect to gain from joining an alliance with stronger players. Strong players may consider it more attractive to stand alone: Within an alliance, the stronger player may have to contribute the lion's share in effort, and the winner prize may have to be shared with the weaker alliance member. We show that this intuition is correct in the context of all-pay auctions with incomplete information. A more surprising effect emerges in case two players of equal strength find themselves together in an alliance, fighting against a stand-alone player. To fight as members of an alliance does not turn two weak players into a stronger player. Rather, it weakens them further in terms of the total effort they can mobilize. Where the free-rider problem may seem to be an additional disadvantage, it turns into an advantage in the all-pay contest: It not only reduces the contest effort of the alliance members but also moderates the effort expended by their joint competitor. Overall, the alliance wins less often but has a higher expected payoff than if both weak players stand alone. Also, the formation of an alliance weakens two equally strong players and can make them even weaker than the outside stand-alone player. But alliance formation can still be beneficial, as it prevents the strong players from heavily competing against each other, in which case they would fully dissipate their rents.

\footnotetext{
${ }^{27}$ The exact threshold for $q$ depends on the cost-sharing arrangement within a collusive alliance.
} 


\section{A Appendix}

\section{A.1 Proof of Proposition 1}

Table 2 describes the equilibrium payoffs in the continuation game if a coalition has been formed. To derive these payoffs we have to distinguish two cases.

Case 1: $2 V_{C}>\max \left\{V_{A}, V_{B}\right\}$. Here, the equilibrium mixed strategies $F_{A B}\left(x_{A}+\right.$ $\left.x_{B}\right)$ and $F_{C}\left(x_{C}\right)$ for the alliance $A B$ and for player $C$, respectively, are given by

$$
F_{A B}(x)=\left\{\begin{array}{cl}
1-\frac{\max \left\{V_{A}, V_{B}\right\} / 2}{V_{C}}+\frac{x}{V_{C}} & \text { for } x=x_{A}+x_{B} \in\left[0, \max \left\{V_{A}, V_{B}\right\} / 2\right], \\
1 & \text { for } x=x_{A}+x_{B}>\max \left\{V_{A}, V_{B}\right\} / 2,
\end{array}\right.
$$

and

$$
F_{C}(x)=\left\{\begin{array}{cl}
\frac{x}{\max \left\{V_{A}, V_{B}\right\} / 2} & \text { for } x \in\left(0, \max \left\{V_{A}, V_{B}\right\} / 2\right], \\
1 & \text { for } x>\max \left\{V_{A}, V_{B}\right\} / 2 .
\end{array}\right.
$$

To confirm that $F_{A B}$ and $F_{C}$ are mutually optimal replies, consider first player $C$. With $F_{A B}$ as in (13), for all $x_{C} \in\left(0, \max \left\{V_{A}, V_{B}\right\} / 2\right]$ we get

$$
E\left(\pi_{C}\left(x_{C}\right)\right)=F_{A B}\left(x_{C}\right) V_{C}-x_{C}=V_{C}-\frac{\max \left\{V_{A}, V_{B}\right\}}{2}+x_{C}-x_{C},
$$

which is independent of $x_{C}$. Efforts $x_{C}>\max \left\{V_{A}, V_{B}\right\} / 2$ lead to strictly lower payoff; also, $x_{C}=0$ yields a lower payoff. Therefore, for player $C$, any mixed strategy $F_{C}$ on $\left(0, \max \left\{V_{A}, V_{B}\right\} / 2\right]$ is an optimal reply to $F_{A B}$.

Now consider player $i$ as one of the alliance players $i \in\{A, B\}$. Let $F_{C}$ and joint effort $x_{A}+x_{B}$ be given. For $x_{i} \in\left(0, \max \left\{V_{A}, V_{B}\right\} / 2-x_{j}\right)$, an increase in own effort $x_{i}$ yields a marginal change in the own expected payoff equal to

$$
\begin{aligned}
\frac{\partial E\left(\pi_{i}\right)}{\partial x_{i}} & =F_{C}^{\prime}\left(x_{i}+x_{j}\right) \frac{V_{i}}{2}-x_{i}=\frac{1}{\max \left\{V_{A}, V_{B}\right\} / 2} \frac{V_{i}}{2}-1 \\
& =\left\{\begin{array}{cl}
0 & \text { if } V_{i}=\max \left\{V_{A}, V_{B}\right\}, \\
-\left(1-\frac{V_{i}}{\max \left\{V_{A}, V_{B}\right\}}\right)<0 & \text { if } V_{i}<\max \left\{V_{A}, V_{B}\right\} .
\end{array}\right.
\end{aligned}
$$

Moreover, for $x_{i}>\max \left\{V_{A}, V_{B}\right\} / 2-x_{j}$, we get $\partial E\left(\pi_{i}\right) / \partial x_{i}=-1 .{ }^{28}$ Accordingly, a player $i$ with $V_{i}<\max \left\{V_{A}, V_{B}\right\}$ yields his maximum expected payoff for $x_{i}=0$, and

\footnotetext{
${ }^{28}$ Note, at this point, that $x_{i}$ and $x_{j}$ are strategically interdependent as regards whether a given $x_{i}$ leads to an $x_{i}+x_{j}$ inside the equilibrium support.
} 
a player $i$ with $V_{i}=\max \left\{V_{A}, V_{B}\right\}$ is indifferent to an increase in $x_{A}+x_{B}$ inside the equilibrium support of $F_{A B}$. Therefore, suppose first that $V_{i}=\max \left\{V_{A}, V_{B}\right\}>V_{j}$. Given $F_{C}\left(x_{C}\right), x_{j}=0$ is a dominant strategy for player $j$; for player $i$, randomization according to $F_{A B}(x)$ is an optimal reply to $F_{C}(x)$ and $x_{j}=0$. If instead $V_{i}=\max \left\{V_{A}, V_{B}\right\}=V_{j}$ then the coordination device applies: If $i$ is in the role of contributor, randomization according to $F_{A B}(x)$ is an optimal reply to $F_{C}(x)$ and $x_{j}=0$. For the non-contributor $j, x_{j}=0$ is the best reply to $F_{C}(x)$ and an effort of $i$ chosen according to $F_{A B}$. We assume that $i$ and $j$ perfectly negatively correlate their decisions to take the contributor role and each of them is in the contributor role in half of the cases. ${ }^{29}$ Then the players' expected payoffs can be stated as

$$
E\left(\pi_{i}\right)=0
$$

for the contributor $i \in\{A, B\}$,

$$
E\left(\pi_{j}\right)=\frac{1}{2} \frac{\max \left\{V_{A}, V_{B}\right\} / 2}{V_{C}} \frac{V_{j}}{2}
$$

for the non-contributor $j \in\{A, B\}$, and

$$
E\left(\pi_{C}\right)=V_{C}-\frac{\max \left\{V_{A}, V_{B}\right\}}{2}
$$

for the stand-alone player $C$.

Case 2: $2 V_{C} \leq \max \left\{V_{A}, V_{B}\right\}$. The mixed strategies $F_{A B}\left(x_{A}+x_{B}\right)$ and $F_{C}\left(x_{C}\right)$ that are mutually optimal replies are

$$
F_{A B}(x)=\left\{\begin{array}{cc}
\frac{x}{V_{C}} & \text { for } x=x_{A}+x_{B} \in\left[0, V_{C}\right] \\
1 & \text { for } x=x_{A}+x_{B}>V_{C}
\end{array}\right.
$$

and

$$
F_{C}(x)=\left\{\begin{array}{cc}
1-\frac{V_{C}}{\max \left\{V_{A}, V_{B}\right\} / 2}+\frac{x}{\max \left\{V_{A}, V_{B}\right\} / 2} & \text { for } x \in\left(0, V_{C}\right] \\
1 & \text { for } x>V_{C}
\end{array} .\right.
$$

To confirm this mutual optimality, consider first player $C$. Given $F_{A B}$ as in (17),

$$
E\left(\pi_{C}\left(x_{C}\right)\right)=F_{A B}\left(x_{C}\right) V_{C}-x_{C}=0
$$

\footnotetext{
${ }^{29}$ Such a correlation device has been discussed and used in the context of all-pay contests by Konrad and Leininger (2011) and by Konrad and Kovenock (2009).
} 
for $x_{C} \in\left[0, V_{C}\right]$, and $E\left(\pi_{C}\right)<0$ for $x_{C}>V_{C}$. Hence, $C$ is indifferent to any $x_{C} \in\left[0, V_{C}\right]$ and strictly prefers any of these effort levels to any higher effort.

Consider player $i \in\{A, B\}$ and suppose first that $V_{i}=\max \left\{V_{A}, V_{B}\right\}$. Assume that $x_{j} \equiv 0$ (to be justified later). Given $F_{C}\left(x_{C}\right)$ as in (18) and $x_{j}=0$, $i$ 's expected payoff for $x_{i} \in\left(0, V_{C}\right]$ is

$$
E\left(\pi_{i}\left(x_{i}\right)\right)=F_{C}\left(x_{i}\right) \frac{V_{i}}{2}-x_{i}=\frac{V_{i}}{2}-V_{C}
$$

and is smaller elsewhere. Accordingly, $i$ is indifferent between all $x_{i}$ in the equilibrium support and may choose $x_{i}$ to generate $F_{A B}(x)$ given $x_{j}=0$. To confirm that $x_{j}=0$ is optimal to $F_{C}$ and the choice of $i$, note that $j$ 's expected payoff for $x_{j} \in\left[0, V_{C}\right]$ is equal to

$$
\begin{aligned}
E\left(\pi_{j}\left(x_{j}\right)\right) & =\frac{V_{j}}{2} \int_{x_{i}=0}^{x_{i}=V_{C}} F_{C}\left(x_{i}+x_{j}\right) d F_{A B}\left(x_{i}\right)-x_{j} \\
& =\frac{V_{j}}{2}\left[\int_{0}^{V_{C}-x_{j}}\left(1-\frac{V_{C}}{V_{i} / 2}+\frac{x_{i}+x_{j}}{V_{i} / 2}\right) \frac{1}{V_{C}} d x_{i}+\left(1-\frac{V_{C}-x_{j}}{V_{C}}\right)\right]-x_{j} .
\end{aligned}
$$

Thus,

$$
\begin{aligned}
\frac{\partial E\left(\pi_{j}\right)}{\partial x_{j}} & =\frac{V_{j}}{2}\left[-\left(1-\frac{V_{C}}{V_{i} / 2}+\frac{V_{C}-x_{j}+x_{j}}{V_{i} / 2}\right) \frac{1}{V_{C}}+\int_{0}^{V_{C}-x_{j}} \frac{1}{V_{i} / 2} \frac{1}{V_{C}} d x_{i}+\frac{1}{V_{C}}\right]-1 \\
& =\frac{V_{j}}{2} \frac{1}{V_{i} / 2} \frac{V_{C}-x_{j}}{V_{C}}-1,
\end{aligned}
$$

which is strictly negative for $V_{j} \leq V_{i}$. (Moreover, $\partial E\left(\pi_{j}\right) / \partial x_{j}=-1$ for $x_{j}>V_{C}$.) Thus, $x_{j}=0$ is $j$ 's best reply to $F_{C}$ and to a choice of $i$ according to $F_{A B}$. As in case 1 , if $V_{i}>V_{j}$, this yields a unique equilibrium in which only $i$ is active and randomizes according to $F_{A B}$. If $V_{i}=V_{j}$, the coordination device assigns the roles of contributor and non-contributor with equal probabilities to $i$ and $j$; the contributor randomizes according to $F_{A B}$ and the non-contributor chooses an effort of zero (which is his optimal reply). Expected payoffs in the candidate equilibrium are

$$
E\left(\pi_{i}\right)=\frac{V_{i}}{2}-V_{C}
$$

for the contributor $i \in\{A, B\}$,

$$
E\left(\pi_{j}\right)=\frac{\max \left\{V_{A}, V_{B}\right\}-V_{C}}{\max \left\{V_{A}, V_{B}\right\}} \frac{V_{j}}{2}
$$


for the non-contributor $j \in\{A, B\}$, and

$$
E\left(\pi_{C}\right)=0
$$

for the stand-alone player $C$.

Using the results in cases 1 and 2, the expected payoffs as a function of the players' valuations follow directly. Recall that $V_{C}=M$. Thus, if $V_{A}=V_{B}<2 M$ then (15) and (16) imply that

$$
E\left(\pi_{A}\right)=E\left(\pi_{B}\right)=\frac{1}{2} 0+\frac{1}{2} \frac{1}{2} \frac{V_{A} / 2}{V_{C}} \frac{V_{A}}{2}
$$

which yields $E\left(\pi_{A}\right)=E\left(\pi_{B}\right)=L^{2} /(16 M)$ if $V_{A}=V_{B}=L$ and $E\left(\pi_{A}\right)=E\left(\pi_{B}\right)=$ $H^{2} /(16 M)$ if $V_{A}=V_{B}=H$. If instead $V_{A}=V_{B}=H>2 M$ then (19) and (20) yield

$$
E\left(\pi_{A}\right)=E\left(\pi_{B}\right)=\frac{1}{2}\left(\frac{V_{A}}{2}-V_{C}\right)+\frac{1}{2} \frac{V_{A}-V_{C}}{V_{A}} \frac{V_{A}}{2}=\frac{H}{2}-\frac{3 M}{4} .
$$

If $V_{A} \neq V_{B}$ and, for instance, $V_{A}>V_{B}$, (15) and (16) yield

$$
E\left(\pi_{A}\right)=0 \text { and } E\left(\pi_{B}\right)=\frac{1}{2} \frac{V_{A} / 2}{V_{C}} \frac{V_{B}}{2}=\frac{1}{8} \frac{H L}{M}
$$

in case of $H<2 M$, and (19) and (20) imply that

$$
E\left(\pi_{A}\right)=\frac{H}{2}-M \text { and } E\left(\pi_{B}\right)=\frac{H-M}{H} \frac{L}{2}
$$

in case of $H>2 M$. The expected payoff of the stand-alone player is equal to zero if $\max \left\{V_{A}, V_{B}\right\}>2 M$ and equal to $V_{C}-\max \left\{V_{A}, V_{B}\right\} / 2$ otherwise.

\section{A.2 Proof of Remark 1}

Suppose that if an alliance is formed, alliance members coordinate on a total effort $x_{A}+x_{B}$ which maximizes the total expected payoff of the alliance given by

$$
\pi_{A}+\pi_{B}=\left\{\begin{array}{cl}
\frac{V_{A}+V_{B}}{2}-\left(x_{A}+x_{B}\right) & \text { if the alliance wins, } \\
-\left(x_{A}+x_{B}\right) & \text { otherwise. }
\end{array}\right.
$$

Note that in equilibrium only the sum $x_{A}+x_{B}$ will be determined; the individual payoffs $\pi_{A}$ and $\pi_{B}$ depend on how the effort is shared. Using the standard logic of the 


\begin{tabular}{ccccc} 
& & & $E\left(\pi_{A}+\pi_{B}\right)$ & $E\left(\pi_{C}\right)$ \\
\hline \hline$V_{A}=L$ & $V_{B}=L$ & & 0 & $M-L$ \\
\hline$V_{A}=H$ & $V_{B}=L$ & and $H+L \leq 2 M$ & 0 & $M-\frac{H+L}{2}$ \\
\hline$V_{A}=H$ & $V_{B}=L$ & and $H+L>2 M$ & $\frac{H+L}{2}-M$ & 0 \\
\hline$V_{A}=L$ & $V_{B}=H$ & and $H+L \leq 2 M$ & 0 & $M-\frac{H+L}{2}$ \\
\hline$V_{A}=L$ & $V_{B}=H$ & and $H+L>2 M$ & $\frac{H+L}{2}-M$ & 0 \\
\hline$V_{A}=H$ & $V_{B}=H$ & $H-M$ & 0 \\
\hline \hline
\end{tabular}

Table A.1: Expected payoffs if players $A$ and $B$ are in an alliance and choose efforts so as to maximize their joint expected payoffs, as a function of the valuations of $A$ and $B$, assuming that the valuation of the stand-alone player $C$ is $V_{C}=M$.

all-pay auction for two strategic players with valuations $V_{A B}=V_{A} / 2+V_{B} / 2$ and $V_{C}$, the unique equilibrium follows from Baye et al. (1996), with expected equilibrium payoffs as given in Table A.1.

Before deriving the equilibrium alliance formation choices we compare the total expected alliance payoff as given in Table A.1 to the expected payoffs of an alliance which chooses the efforts non-cooperatively under complete information (Proposition 2; Table 2). Here, we have to distinguish different cases, but it is straightforward to verify that total expected payoff of a collusive alliance (as in Table A.1) is strictly higher than the total expected payoff under non-cooperative effort choices (as in Table 2) if and only if at least one of the alliance players $A$ and $B$ has a high valuation and $H$ is sufficiently large.

Part (i): Suppose first that $V_{i}=L$. Then $i$ 's expected payoff when standing alone is zero and $i$ will get at least zero when forming an alliance. In fact, if $V_{j}=$ $H>2 M-L, j \in\{A, B\}, j \neq i$, then the total expected alliance payoff under joint payoff maximization is strictly positive; depending on how $i$ and $j$ share the effort cost (depending on the exact combination $\left.\left(x_{A}, x_{B}\right)\right), i$ can achieve a strictly positive payoff. Thus, players $i$ with $V_{i}=L$ are at least weakly better off for $\lambda_{i}=1$ than for $\lambda_{i}=0$. Now suppose that $V_{i}=H$. If $V_{j}=H$, then $\lambda_{j}=0$ in the candidate equilibrium and $i$ 's choice is inconsequential since no alliance is formed. If $V_{j}=L$, however, $i$ gets $H-M$ when standing alone and at most $(H+L) / 2-M<H-M$ when forming an alliance which maximizes joint payoffs. Therefore, for $V_{i}=H, i$ 
strictly prefers $\lambda_{i}=0$ over $\lambda_{i}=1$. Altogether, this shows that the type- 1 equilibrium always exists.

Part (ii): From the previous paragraph it already follows that player $i$ with $V_{i}=L$ is (weakly) better off when forming an alliance than when standing alone. Therefore, we only need to consider the case of $V_{i}=H$. If $V_{j}=H$, then in the candidate equilibrium where $\lambda_{j}=1, i$ can get a strictly positive payoff when forming an alliance but gets zero when deviating to $\lambda_{i}=0$. Assuming that $A$ and $B$ share the cost of alliance effort equally in case of $V_{A}=V_{B}$, $i$ 's expected payoff in the alliance is $(H-M) / 2$ (compare Table A.1). ${ }^{30}$ If $V_{j}=L$, however, $i$ gets at most $\max \left\{\frac{H+L}{2}-M, 0\right\}$ in the candidate equilibrium with $\lambda_{i}=1$, but gets $H-M$ if he deviates to $\lambda_{i}=0$. Thus, the type-2 equilibrium exists if and only if the probability that $j$ is a low type is sufficiently low (that is, $q$ is sufficiently high).

To determine the exact threshold above which the type-2 equilibrium exists, we have to make an assumption as to which equilibrium is selected in case an alliance is formed and $V_{A} \neq V_{B}$. As an example, suppose that if $V_{i}=H>V_{j}=L$ then $i$ and $j$ share the effort $x_{A}+x_{B}$ according to their relative valuations, that is, $x_{i}=$ $\left(x_{A}+x_{B}\right) V_{i} /\left(V_{A}+V_{B}\right)$. Then, if $H+L \leq 2 M$, we get $E\left(\pi_{A}\right)=E\left(\pi_{B}\right)=0$. If, however, $H+L>2 M$, total expected alliance payoff is strictly positive; the sharing rule on the effort cost implies that $E\left(\pi_{i}\right)=V_{i} / 2-M V_{i} /\left(V_{A}+V_{B}\right)$. Therefore, if $H+L \leq 2 M$ then player $i$ with $V_{i}=H$ does not want to deviate to $\lambda_{i}=0$ if and only if

$$
q\left(\frac{H}{2}-\frac{M}{2}\right)+(1-q) 0 \geq q \cdot 0+(1-q)(H-M),
$$

which is equivalent to $q \geq 2 / 3$. If instead $H+L>2 M, i$ with $V_{i}=H$ does not want to deviate to $\lambda_{i}=0$ if and only if

$$
\left(\frac{H}{2}-\frac{M}{2}\right)+(1-q) 0 \geq q\left(\frac{H}{2}-\frac{H}{H+L} M\right)+(1-q)(H-M),
$$

that is, if and only if $q \geq \tilde{q}$ where

$$
\tilde{q}=1-\frac{(H+L)(H-M)}{H^{2}+H L-2 M L+(H+L)(H-M)} .
$$

\footnotetext{
${ }^{30}$ In fact, except for the limit case in which $j$ does not contribute at all to total alliance effort, $i$ 's expected equilibrium payoff is strictly above zero.
} 


\section{References}

[1] Alcalde, José, and Matthias Dahm, 2010, Rent seeking and rent dissipation: A neutrality result, Journal of Public Economics, 94(1-2), 1-7.

[2] Amann, Erwin, and Wolfgang Leininger, 1996, Asymmetric all-pay auctions with incomplete information: The two-player case, Games and Economic Behavior, 14(1), 1-18.

[3] Baik, Kyung Hwan, and Jason F. Shogren, 1992, Strategic behavior in contests - comment, American Economic Review, 82(1), 359-362.

[4] Baye, Michael R., Dan Kovenock, and Casper G. de Vries, 1996, The all-pay auction with complete information, Economic Theory, 8(2), 291-305.

[5] Baye, Michael R., Dan Kovenock, and Casper G. de Vries, 2012, Contests with rank-order spillovers, Economic Theory, 51(2), 315-350.

[6] Bearce, David H., Kristen M. Flanagan, and Katharine M. Floros, 2006, Alliances, internal information, and military conflict among member-states, International Organization, 60(3), 595-625.

[7] Bergstrom, Theodore C., Lawrence Blume and Hal Varian, 1986, On the private provision of public goods, Journal of Public Economics, 29(1), 25-49.

[8] Bissonnette, Annie, Susan Perry, Louise Barrett, John C. Mitani, Mark Flinn, Sergey Gavrilets and Frans B.M. de Waal, 2015, Coalitions in theory and reality: a review of pertinent variables and processes, Behaviour, 152, 1-56.

[9] Davis, Douglas D., and Robert J. Reilly, 1999, Rent-seeking with non-identical sharing rules: An equilibrium rescued, Public Choice, 100(1-2), 31-38.

[10] Esteban, Joan M., and Debraj Ray, 2001, Collective action and the group size paradox, American Political Science Review, 95(3), 663-672.

[11] Esteban, Joan M., and József Sákovics, 2003, Olson vs. Coase: coalitional worth in conflict, Theory and Decision, 55(4), 339-357.

[12] Fudenberg, Drew, and Jean Tirole, 1984, The fat-cat effect, the puppy-dog ploy, and the lean and hungry look, American Economic Review, Papers and Proceedings, 74(2), 361-366.

[13] Hart, Sergiu, and Mordecai Kurz, 1983, Endogenous formation of coalitions, Econometrica, 51(4), 1047-1064. 
[14] Herbst, Luisa, Kai A. Konrad, and Florian Morath, 2015, Endogenous group formation in experimental contests, European Economic Review, 74, 163189.

[15] Hillman, Arye, and John G. Riley, 1989, Politically contestable rents and transfers, Economics \& Politics, 1(1), 17-39.

[16] Hirshleifer, Jack, 1983, From weakest-link to best-shot: the voluntary provision of public goods, Public Choice, 41(3), 371-86.

[17] Hurley, Terrance M., and Jason F. Shogren, 1998, Asymmetric information contests, European Journal of Political Economy, 14(4), 645-665.

[18] Kolmar, Martin, and Andreas Wagener, 2013, Inefficiency as a strategic device in group contests against dominant opponents, Economic Inquiry, 51(4), 2083-2095.

[19] Konishi, Hideo, and Debraj Ray, 2003, Coalition formation as a dynamic process, Journal of Economic Theory, 110(1), 1-41.

[20] Konrad, Kai A., 2002, Investment in the absence of property rights; the role of incumbency advantages, European Economic Review, 46(8), 1521-1537.

[21] Konrad, Kai A., 2004, Altruism and envy in contests: an evolutionary stable symbiosis, Social Choice and Welfare, 22(3), 479-490.

[22] Konrad, Kai A., 2012, Information alliances in contests with budget limits, Public Choice, 151(3-4), 679-693.

[23] Konrad, Kai A., 2014, Strategic aspects of fighting in alliances, in: Wärneryd, K. (ed.), The Economics of Conflict, CESifo Seminar Series. MIT Press, Cambridge \& London, 1-22.

[24] Konrad, Kai A., and Dan Kovenock, 2009, The alliance formation puzzle and capacity constraints, Economics Letters, 103(2), 84-86.

[25] Konrad, Kai A., and Wolfgang Leininger, 2011, Self-enforcing norms and efficient non-cooperative collective action in the provision of public goods, Public Choice, 146(3-4), 501-520.

[26] Konrad, Kai A., Wolfgang Peters, and Karl Wärneryd, 2004, Delegation in firstprice all-pay auctions, Managerial and Decision economics, 25(5), 283-290. 
[27] Kovenock, Dan, and Brian Roberson, 2012, Coalitional Colonel Blotto games with application to the economics of alliances, Journal of Public Economic Theory, 14(4), 653-676.

[28] Kovenock, Dan, Florian Morath, and Johannes Münster, 2015, Information sharing in contests, Journal of Economics \& Management Strategy, 24(3), 570-596.

[29] Malueg, David A., and Andrew J. Yates, 2004, Rent seeking with private values, Public Choice, 119, 161-178.

[30] Malueg, David A., and Huiling Zhang, 2015, Limited-membership informationsharing alliances in contests, Working Paper.

[31] Meirowitz, Adam, 2008, Electoral contests, incumbency advantages, and campaign finance, Journal of Politics, 70(3), 681-699.

[32] Morath, Florian, and Johannes Münster, 2013, Information acquisition in conflicts, Economic Theory, 54, 99-129.

[33] Nitzan, Shmuel, 1991, Collective rent dissipation, Economic Journal, 101(409), 1522-1534.

[34] Olson, Mancur, and Richard Zeckhauser, 1966, Economic theory of alliances, Review of Economics and Statistics, 48(3), 266-279.

[35] Ray, Debraj, and Rajiv Vohra, 1997, Equilibrium binding agreements, Journal of Economic Theory, 73(1), 30-78.

[36] Ray, Debraj, and Rajiv Vohra, 2015, The farsighted stable set, Econometrica, 83(3), 977-1011.

[37] Salant, Stephen W., Sheldon Switzer, and Robert J. Reynolds, 1983, Losses from horizontal merger: the effects of an exogenous change in industry structure on Cournot-Nash equilibrium, Quarterly Journal of Economics, 98(2), 185199.

[38] Serena, Marco, 2015, Harnessing beliefs to stimulate efforts, Working Paper, available at SSRN: http://ssrn.com/abstract $=2686543$.

[39] Siegel, Ron, 2009, All-pay contests, Econometrica, 77(1), 71-92.

[40] Skaperdas, Stergios, 1998, On the formation of alliances in conflict and contests, Public Choice, 96(1-2), 25-42. 
[41] Thompson, William R., 2001, Identifying rivals and rivalries in world politics, International Studies Quarterly, 45, 557-586.

[42] Tullock, Gordon, 1980, Efficient rent seeking, in: James M. Buchanan, Robert D. Tollison, and Gordon Tullock (eds.), Toward a Theory of the Rent-seeking Society, Texas A\&M University Press, College Station, 97-112.

[43] Vives, Xavier, 2005, Complementarities and games, new developments, Journal of Economic Literature, 43(2), 437-479.

[44] Wasser, Cédric, 2013, Incomplete information in rent-seeking contests, Economic Theory, 53(1), 239-268.

[45] Weber, Robert, 1985, Auctions and Competitive Bidding, Proceedings of Symposia in Applied Mathematics, 33, 143-170. 